\title{
A MORTE É UM MESTRE QUE VEIO DA ALEMANHA: ENSAIO SOBRE A ALEGORIA NA POESIA DE CELAN
}

\author{
Maria João Cantinho ${ }^{1}$ \\ E grita toquem mais doce a música da morte a morte é um mestre/ \\ Que veio da Alemanha(...) \\ (Celan, Sete Rosas mais Tarde, 1996, pp. 16, 17) ${ }^{2}$ \\ RESUMO
}

\begin{abstract}
A partir da análise do poema Todesfuge (Fuga da Morte) de Celan, procuro compreender a estrutura alegórica da sua obra. A escrita de Celan é fruto de uma experiência vivida do choque, profundamente traumática. Tem como matriz o holocausto e só uma compreensão alegórica da sua linguagem permite uma compreensão mais adequada, no sentido em que Walter Benjamin toma a alegoria: como a apresentação do rosto da morte e da experiência arruinada do homem. Mudez, tristeza e horror, eis os elementos que configuram essa poética que se configura também como um gesto de rememoração e ético.
\end{abstract}

Palavras-chave: Poesia, Alegoria, Experiência.

\section{DEATH IS A TEACHER WHO CAME FROM GERMAN: ESSAY ON ALLEGORY IN THE POETRY OF CELAN}

\begin{abstract}
From the analysis of the poem Todesfuge (Death Fugue) of Celan, this work seeks to understand the allegorical structure of this work. Celan's writing is the result of an experience of a profoundly traumatic shock. The holocaust is it matrix and only an understanding of its allegorical language allows a more adequate understanding, in the sense in which Walter Benjamin understand the allegory: the presentation of the face of death and the experience of a ruined man. Silence, sadness and horror, there are the elements that make up this poetry which is configured also as a gesture of remembrance and ethical
\end{abstract}

Keywords: Poetry, Allegory, Experience,

\footnotetext{
1 Professora auxiliar no lade (Creative Institut of Lisbon).

2 Sigo a tradução de João Barrento e Yvette Centeno, de Mohn und Gedächtnis(Papoila e Memória),Sete Rosas Mais Tarde, pp. 16, 17: "Er ruft spielt süßer den Tod ist ein Meister aus Deutschland".
} 
A obra de Paul Celan, como sabemos, entrosa numa tradição poética que remonta a Wilhelm von Humboldt (1767-1835) e ganha uma notável expressão na hermenêutica de autores do século XX como Gadamer, Heidegger, George Steiner ou, ainda, Walter Benjamin ${ }^{3}$. Não sendo filósofo, mas sim poeta, a sua obra convocou o pensamento de vários autores, que perfilham uma mesma "constelação" de pensadores. Não é de interesse enumerar todos os autores que tomaram Celan como matriz de pensamento, mas antes compreender o que filósofos e pensadores como Levinas (Levinas, 2003), Blanchot (Blanchot, 1984), Derrida (Derrida, 1986), Steiner, entre outros, inúmeros, foram beber em Celan e o modo como se "apropriaram" da sua obra. Se alguns tomam em Celan a questão ética do Outro Levinas - e do Reconhecimento, outros abordam-no pelo lado do judaísmo (não no sentido redutor da Shoah), nos elos que se entranham e impregnam a linguagem celaniana, isto é, relativamente à ideia da simbologia ${ }^{4}$ e da visão cabalística da linguagem. Outros procurarão, ainda, a tradição hermética da linguagem e o modo como ela se enleia na poética celaniana. Na diversidade das perspectivas e nesse olhar caleidoscópico que incide sobre o autor, estão contidas várias portas de entrada, igualmente legítimas, contribuindo para pôr em relevo a importância e o significado do autor e da sua poética, bem como a inesgotabilidade (e actualidade) das possibilidades da sua leitura/interpretação. A sua linguagem é radicalmente hermética, bem como a simbologia do seu universo, o que exige do leitor uma atenção redobrada e um largo fôlego, que não se compadece com a leitura rápida. A crueza de uma linguagem que vive da dor latente da experiência do choque e da memória, nua e cortante como uma navalha acerada, recai sobre a própria língua e asfixia-a, desarticula-a, violentando-a para a obrigar a significar. Não é o embelezamento poético que Celan busca, mas a nudez da verdade, tal como ele a define no texto "Meridiano". Também o Ser é aqui desarticulado e o próprio tempo 6 .

${ }^{3}$ Este, como exprimiu o seu desejo, numa carta ao seu amigo Gershom Scholem, reclamava para si o estatuto, não de filósofo, mas sim de crítico literário.

4 É durante a década de sessenta que Paul Celan estuda Gershom Scholem e aprofunda a leitura dos textos da Cabala, tornando-se mais explícita a simbologia cabalística nos seus textos. Veja-se o magnífico prefácio de Yvette Centeno à tradução portuguesa da poesia de Celan, em Sete Rosas mais Tarde, ed. Cotovia, Lisboa, 1993. Neste ensaio referencial, a autora explora a relação da poesia de Celan com a simbologia cabalística e, ainda, da alquimia.

5 Celan, Paul, Le Méridien \& Autres Proses, Seuil, Paris, 2002, p. 44 : «Seule des mains vraies écrivent de vrais poèmes. Je ne vois pas de différence entre une poignée de main et un poème. »

6 Tomado como experiência de tempo cheio, o tempo da plenitude do Ser heideggeriano. 
Na poesia de Celan, não existe qualquer possibilidade de redenção nem amor, como o diz Yvette Centeno, ao assinalar essa "fractura" (Centeno, 1996, p. XXV) ontológica:

O amor está morto na obra de Celan. Perdeu a qualidade redentora. O que dele fica são apenas fragmentos, imagens que não se ordenam numa estrutura superior unificada. Porque esse é o limite que atingem, o limiar que ultrapassam: o da unificação harmoniosa de um universo e numa relação de que 0 amor foi brutalmente cortado. (Centeno, 1996, p. XXV)

Assinalo essa "fractura" a que a citada autora se refere como o alimento essencial da sua poesia, um saber saturnino que lhe confere, desde logo, o carácter profundamente alegórico, isto é a "experiência arruinada" a que Celan quer dar voz. Como dar voz - e procurar a harmonia - num mundo em que ela já há muito se dissipou? A questão tangencia a de Adorno, quando ele afirmava que seria um acto de barbárie escrever poesia após Auschwitz.Celan nunca pretendeu branquear essa experiência do horror, mas sim, de algum modo possível, resgatá-la, num sentido alegórico $^{7}$ e judaico, como veremos. Encontramos em Walter Benjamin uma das definições mais completas do que é a alegoria enquanto modus operandi, distinguindo-o do procedimento simbólico:

\begin{abstract}
Enquanto no símbolo, com a transfiguração da decadência, o rosto transfigurado da natureza se revela fugazmente na luz da redenção, na alegoria o observador tem diante de si a faccies hipocrática da história como paisagem primordial petrificada. A história, com tudo aquilo que desde 0 início tem em si de extemporâneo, de sofrimento e de malogro, ganha expressão na imagem de um rosto - melhor, de uma caveira(....). ${ }^{8}$
\end{abstract}

É neste sentido que Celan se aproxima da teoria benjaminiana da alegoria, pelo facto de "apresentar" a história no rosto hediondo da morte (na figura do extermínio judaico), sem ilusões. O rosto moribundo (faccies hipocrática) da história, eis o que se apresenta na poética de Celan. A morte, em toda a sua violência e

\footnotetext{
${ }^{7}$ Não é a minha intenção desenvolver este aspecto da alegoria da poética de Celan, pelo menos num sentido exaustivo, mas sim remeter o leitor para a riqueza das leituras da poesia de Celan, partindo de uma análise de alguns textos de Walter Benjamin, um dos teóricos incontornáveis do século XX no estudo da modernidade. Este foi um aspecto que explorei num texto que publiquei recentemente (Cantinho, M.J., "A Frágil Luz que nos Espera", in Golpe d'asa, №1, 2012).

8 Benjamin, Walter, A Origem do Drama Trágico Alemão, tradução de João Barrento, ed. Assírio \& Alvim, Lisboa, 2004, p. 180. Nesta obra, Walter Benjamin vai analisar o género literário do drama barroco (ou trágico, como o traduz João Barrento, a partir do termo Trauerspiel), estabelecendo uma tese que diferencia o simbólico do alegórico e reabilitando o procedimento alegórico como o modo estético de representação da morte, da decadência e do horror, da ruína. Se o simbólico
} 
inevitabilidade, como catástrofe, é o tema/matriz fundamental da sua poética. Celan nunca quis embelezar os acontecimentos, mas sim "mostrar", apresentar esse rosto desfigurado, ainda que reconfigurando poeticamente o seu objecto. Alegórica, em todo o sentido do termo, procurando salvar na memória o que se encontrava naturalmente destinado ao esquecimento. É aí que a vocação e o impulso alegórico se apresentam, de novo, como uma «chave» do saber, comparando, ainda, Benjamin esta actividade à do crítico:

O que perdura [na alegoria] é o raro pormenor das referências alegóricas:
um objecto de saber, alojado nas construções planificadas das ruínas. A
crítica é mortificação das obras. Isto é confirmado pela essência das obras
alegóricas, mais do que por quaisquer outras. Mortificação das obras: não -
como o queriam os românticos - o despertar da consciência nas obras
vivas, mas a implantação do saber naquelas que estão mortas. A beleza
que perdura é um objecto de saber. (Benjamin, A Origem do Drama Trágico
Alemão (Obras Escolhidas), 2004, p. 197).

Isto é, se a organicidade do vivo aparece destruída, a ideia não é a da mera exposição, mas sim o resgate do que "perdura", inscrevendo-o numa outra temporalidade: a da eternidade, a do saber durável, a da memória, ou melhor, da rememoração. O alegorista é o que olha o vivo e nele antecipa a morte, sabendo que tudo se destina à catástrofe e, por isso, quer salvar as coisas e os seres, inscrevendo-as numa outra ordem, durável. Como diz Benjamin, "nas suas mãos, a coisa transforma-se em algo de diverso, através dela se fala de algo de diverso e ela torna-se a chave que lhe dá acesso a um saber oculto que ele venera na coisa como o seu emblema"(ibidem, p. 199). Nesse sentido se pode tomar a simbologia da poética de Celan, aludindo - entre muitas outras - à poderosíssima metáfora do "leite negro da madrugada" (Celan, Sete Rosas mais Tarde, 1996, p. 17), no poema Todesfuge, esse oxímoro que contrapõe o sentido de leite (o leite branco, fonte de vida) com o negro, como o fel. O negro, como o diz Maria do Sameiro Barroso, num ensaio sobre Paul Celan, é a "não-cor ou a cor da destruição, a cor da morte e simboliza a perda da esperança". Ao usar este oxímoro, Celan faz cindir a unidade do verso e da linguagem, violentando-a, remetendo para a frieza da execução que esperava os judeus. O que lhes resta, não é o repouso do corpo na terra, mas sim "um túmulo nos ares", bem como há ainda a terrível metáfora do contraste dos

reenvia para a totalidade e para a harmonia, já a alegoria reenvia exactamente para o inverso: a dilaceração, o fragmento morto e inerte. 
cabelos, como assinala Yvette Centeno (Centeno, 1996, p. XVI), "a marca da diferença que justifica o crime: "os cabelos de oiro de Margarete" (Celan, Sete Rosas mais Tarde, 1996, p. 17) e "os cabelos de cinza de Sulamith" (idem), contrastando a pureza do primeiro com a alusão "à treva dos fornos crematórios"(idem). As imagens utilizadas remetem para outras significações, procedimento que é próprio do alegorista e que faz, ao mesmo tempo, rasgar o poema, nos seus versos, dilacerando o sentido habitual e obrigando a língua a significar, inscrevendo-a assim numa outra ordem de significação.

Há, por outro lado, neste impulso alegórico, um outro aspecto que se prende com a ideia de resgate e que tem que ver com a violência do imperativo judaico: "Zachor, lembra-te!". Este reenvia para a exigência ética de não ser cúmplice com o esquecimento dos factos e Celan tinha bem presente essa ameaça. Por isso, para ele, só a rememoração, tomada como gesto ético e de restituição simbólica, permite um resgate da experiência das vítimas. Nesse sentido, a sua obra irá permanecer como uma das grandes referências do século $X X$, colocando questões tão incontornáveis como a "indizibilidade" da experiência vivida (e Celan ousa dizê-lo). A linguagem é, assim, vivida como a dimensão mais essencial do humano, levada também a uma dimensão de transgressão e de combate $^{10}$, no sentido, em que ela tem de dizer o que é indizível, o insuportável, a experiência vivida ${ }^{11}$. Por isso, no universo de Celan, o amor, Deus e outros conceitos, que se enleiam com o de esperança, não existem. A sua poética é a de uma "fractura irremediável", que o conduz apenas à escuridão e à mudez da palavra, na sua fase final. Como o diz, de forma admirável, Yvette Centeno, "A treva e o silêncio pairam sobre o seu Verbo que paira, por sua vez, sobre o vazio. O que foi já não é e não será nunca mais." (Centeno, 1996, p. XXVII).

É esse reconhecimento que nos toca na poesia de Celan, como uma espécie de olhar - alegórico - que oscila entre o desejo de redimir os mortos e a

9 Barroso, Maria do Sameiro e Ivo Miguel, Todesguge de Paul Celan, Triplo V (http://triplov.com/letras/maria_do_sameiro/celan/paul_celan.htm).

${ }^{10}$ Ideia que é defendida por Jean Bollack, na sua obra sobre a poética de Celan, "Poesía contra Poesía", ?

${ }^{11}$ Remeto aqui, uma vez mais, o leitor para os textos benjaminianos sobre a experiência do choque, ressaltando, precisamente o seu ensaio Der Erzahler (O Narrador), onde Benjamin descreve a mudez dos que regressam das trincheiras e que não conseguem partilhar a experiência vivida, sob o choque. Relembro, ainda, os rostos e a mudez das vítimas dos campos de concentração, quando foram libertadas pelos Aliados, no final da Segunda Grande Guerra. É deste "indizível" que aqui falamos. 
impossibilidade de levar a cabo essa tarefa. Ou, comparando aqui a poética celaniana com a imagem benjaminiana do anjo da história ${ }^{12}$, aquele que olha alucinadamente o que, por um lado, deseja salvar, e que, por outro, sabe ser impossível, arrastado na vertigem do progresso e de asas aprisionadas.

A experiência da 'fractura da linguagem' foi vivida por Celan de uma forma devastadora. É bem no texto "Alocução de Bremen" que ele dá conta desta travessia pelo "terrível mutismo", a pelas "mil trevas de palavras portadoras de morte" (Celan, Le Méridien \& Autres Proses, 2002, p. 56). Esta experiência, de que tão bem falam Derrida, Steiner (Langage et Silence), Jean Bollack (Poesía contra poesia. Celan y la literatura), Lacoue-Labarthe (La Poésie comme Expérience), Agamben (Le Langage et la Mort), Blanchot (sobretudo no livro que é dedicado a Celan, Le Dernier à Parler) aproxima Celan da experiência poética de Hölderlin ${ }^{13}$.

No texto Arte Poética, Meridiano e outros textos, Paul Celan cruza o seu pensamento com o de Heidegger e Levinas, numa tentativa de (re)definição do "ser do poema", que nos remete para a dificuldade do poeta. "le poème montre, à l'évidence, une forte propension à se taire."14 Nesse texto extraordinário, pela clareza e inequivocidade das suas posições, Celan dá conta da natureza da poesia. Inclusive dá-nos conta do seu conhecimento dos textos benjaminianos ${ }^{15}$, sobretudo do seu texto sobre Kafka (Celan, Le Méridien \& Autres Proses, 2002, p. 77).

O poeta é dominado pelo pathos, que é a experiência da linguagem, naquilo que nela confina - e com ela se entrelaça, obviamente - com a existência da realidade. Como o próprio Celan o diz, em Meridiano :

\footnotetext{
${ }^{12}$ Como ela se apresenta na tese IX de "Sobre o Conceito de História", in Benjamin, Walter, Gesammelte Schriften, I, 2, Suhrkamp Verlag, Frankfurt, 1972, pp. 697, 698: "Há um quadro de Klee que se chama "Angelus Novus". Nele está apresentado um anjo, que parece como se estivesse prestes a afastar-se de algo no qual crava os olhos. Os seus olhos estão muito abertos, a sua boca está aberta e as suas asas estiradas. O anjo da história deve ter este apecto. Quando, diante de nós, surge uma cadeia de acontecimentos, nesse momento vê ele uma única catástrofe, que incansavelmente acumula destroços sobre destroços e estes arrojam-se aos seus pés. Ele bem gostaria de se demorar, de erguer os mortos e de juntar os destroçados. Do paraíso, porém, sopra uma tempestade, que se prende nas suas asas e que é tão forte que o anjo já não as pode fechar. Esta tempestade arrasta-o irresistivelmente para o futuro, ao qual ele volta as costas, enquanto à sua frente cresce 0 monte de destroços. Isso a que chamamos progresso é esta tempestade" (tradução de João Barrento in O Anjo da História, ed. Assírio \& Alvim, Lisboa, 2008, pp. 12/13).

${ }^{13}$ Não foi por acaso que Nelly Sachs o apelidou de Hölderlin contemporâneo.

${ }^{14}$ Celan, Paul, "Le Méridien", in Le Méridien \& Autres Proses, traduit de l'allemand et annoté par Jean Launay, ed.Seuil, Paris, 2002, p. 75.

${ }^{15}$ É bem possível, não sabemos bem se Celan leu atentamente Benjamin e até que ponto a teoria benjaminiana da alegoria pode tê-lo influenciado (se é que tal aconteceu de facto). O certo é que a
} 
Le poème est solitaire. II est solitaire et en chemin. Celui qui l'écrit l'escorte jusqu'au bout.

Par cela même, et dès maintenant, ne voit-on pas que le le poème a lieu dans la rencontre - dans le secret de la rencontre ?

Le poème veut aller vers un autre, il a besoin de cet autre, il en a besoin en face de lui. Il est à sa recherche, il ne s'adresse qu'à lui.

(...)

Le poème devient (...) un dialogue - souvent c'est un dialogue désespéré.

(Celan, Le Méridien \& Autres Proses, 2002, pp. 76, 77)

É bem da solidão que Celan nos fala, uma solidão irremediável e que procura sair de si. Philippe Lacoue-Labarthe compara essa solidão, existencial, ontológica, e não meramente psicológica, com a de Hölderlin: «Même solitude, et même douleur, que celles qu'éprouva pour finir Hölderlin lorsque qu'il eut succumbé à l'excès d'éloquence et fut submergé - reduit au silence - par le pathos sacré ${ }^{16}$. A mesma solidão que condenou Hölderlin ao silêncio, mas em Celan, que reconhece na língua as "palavras portadoras da morte" (Celan, Le Méridien \& Autres Proses, 2002, p. 56), persiste o desejo do encontro. A língua não apenas é um meio convencional para a comunicação e para a orientação, mas sobretudo é, ela própria, criadora de novos lugares, define e, como ele diz, serve "para projectar a realidade diante de mim." ( $p$. 57). Neste sentido, ela configura-se como movimento de apropriação, de encaminhamento, em busca de uma direcção. E se, o poema não existe "fora do tempo" (idem), reenvia, no entanto, para o infinito, "procura passar através do tempo - através, não sobre" (idem). Essa dimensão simultaneamente mundana e transcendente do poema, paradoxal condição que the confere também a universalidade, é o seu alimento essencial e é também uma condição fundamental da possibilidade da poesia, como veremos.

É o princípio dialógico do poema que o subtrai à clausura em que ele tende a encerrar-se, à solidão que Ihe está na origem. A questão aqui colocada é ainda a da própria possibilidade da poesia e prende-se com a anterior. Se, por um lado, «le poème aujourd'hui (...) montre, à l'évidence, une forte propension à se taire(...)" (Celan, Le Méridien \& Autres Proses, 2002, p. 75), por outro lado, «il ne peut s'y tenir qu'en arrachant sans cesse de son déjà plus vers son encore.» (idem). Tal significa que a possibilidade da poesia radica precisamente nessa retirada ou saída de si (Lacoue-Labarthe, 1986, p. 50). Esta saída para fora de si mesmo significa 
também, como o diz o autor, relembrando O Meridiano, sair «para fora do humano», no sentido do acesso à transcendência do Dasein. Diz Celan:

\begin{abstract}
O poema pode, pois ele é um modo de aparição da linguagem, enquanto tal, dialógico por essência, ser uma garrafa no mar, posta na água na crença - nem sempre feita de esperanças certas - que ela poderia ser em qualquer lugar e em qualquer tempo arrastada para uma terra, TerraCoração, talvez." (Celan, Le Méridien \& Autres Proses, 2002, p. 57).
\end{abstract}

Por um lado; a linguagem e a poesia, em particular, aparecem-lhe como possibilidade de abertura para o outro, como responsabilidade, no seu sentido mais pleno, como Levinas e Lacoue-Labarthe muito bem interpretaram. Por outro, a linguagem aparece a Celan como uma ferida não cicatrizada (e nem sequer cicatrizável). Tome-se, novamente o poema Todesfuge cujo título original era Tango da Morte. Tendo sido traduzido para o romeno como Tangoul Mortii, este era o nome de um tango composto pela orquestra de um campo de concentração, sob as ordens de um tenente às ordens da SS. Foi precisamente em alusão a esse tango, que simbolizava o extermínio, que Celan compôs toda a estrutura do seu poema como uma fuga ${ }^{17}$. Como acrescenta, ainda, Felstiner, "para Celan, chamar ao poema «Tango da Morte» era uma forma de anular a dança que fascinava a Europa durante a sua infância - a essência da vida como urbana, graciosa e nonchalant” (idem). Hitler preferia o tango à "decadência" do jazz negro.

Existe ainda, implícita na construção deste poema, uma profunda tradição da cultura alemã e austríaca, que se encontra presente em Schubert, no seu lieder "Der Tod und Das Mädchen", Wagner e "Ein deutsches Requiem" de Brahms, em Mahler, em "Kindertotenlieder" (Felstiner, 2001, p. 33). Dessa tradição macabra e alegórica que fascinou o jovem Paul Celan fala-nos também a sua amiga Edith Silbermann, no seu texto "Rencontre avec Paul Celan"18, referindo a representação pictórica de

${ }^{16}$ Lacoue-Labarthe, Philippe, La Poésie comme Expérience, Christian Bourgois Éditeur, Paris, 1986.

${ }^{17}$ Felstiner dá-nos conta disso em Paul Celan, Poet, Survivor, Jew, p. 28. Na revista romena, Contemporanul, onde foi publicada a primeira tradução do poema (por Petre Solomon), em Maio de 1947, sob o título "Tango de Morte", um ano antes da publicação do original, uma nota de apresentação do tradutor dizia que o poema publicado era construído a partir da evocação de um facto real. Um grupo de prisioneiros, nesse campo, era obrigado a cantar canções nostálgicas enquanto os outros abriam valas comuns.

${ }^{18}$ Rencontre avec Paul Celan", in Europe, no 861, 862, Ed. Europe, Paris, 2001, p. 13 : « Un jour, revenant à Paris, Celan fit halte à Munich et pris rendez-vous avec Achim dans le café Hofgarten. Ils en vinrent à parler du vers tant controversé : « la mort est un maître d'Allemagne ». II jeta un coup d'œil circulaire dans le café et dit ensuite à mi-voix que son poème s'inscrivait dans la tradition des poèmes allemands de danse macabre, que ce vers faisait référence à un poème de ce genre datant du $\mathrm{XVl} \mathrm{l}^{\mathrm{e}}$ siècle, et dans lequel la mort était gratifiée du titre de «maître » ». 
Hans Holbein, nas gravuras intituladas «Simulacros da Morte» e que nos remetem, de forma muito directa e inequívoca para o verso "A morte é um mestre que vem da Alemanha". A esse propósito, cita Edith Silbermann uma passagem de Heinz Piontek, no seu romance Dichterleben ${ }^{19}$.

Sem pretender abordar de forma exaustiva todas as interpretações e leituras, que entrosam numa tradição fortemente alegórica de que Celan tinha plena consciência, ressalto a importância de alguns factos para a compreensão do poema, bem como o modo como desagua nele, não apenas o acontecimento nu, o facto em si, mas sim todo um horizonte de sentido que o contextualiza e que permite uma compreensão mais ampla ao leitor. Nesse contexto, na forma como convoca toda a tradição da cultura alemã, a morte configura-se como protagonista central. Ela é apresentada como um Mestre, que arquitecta uma "dança macabra" em que as diferenças de classes desaparecem, ante o seu veredicto final. O enigmático termo de "Mestre", escolhido por Paul Celan, convoca vários significados (Deus, demiurgo, Cristo, rabi, professor, maestro, alquímico, maçónico, etc.), o que nos lança a nós, seus leitores, numa certa perplexidade. Há um lado evidente e que é a orquestração da morte nos campos de concentração, praticada pelos alemães nazis. Porém, o modo como Celan usa a metáfora da "morte como mestre", vinda da Alemanha, remete para uma apresentação e uma reconfiguração poética alegórica, elevada à sua máxima potência. Não é apenas a morte física, a destruição dos judeus nos fornos crematórios, que "cavam túmulos nos ares", mas é também a forma como esse acontecimento se crava na memória de um povo e, também, na linguagem e no modo como a faz naufragar. Isto é, não é apenas a figura física da morte ou, num sentido mais amplo, da barbárie, mas a morte, enquanto princípio destruidor ou olhar de medusa, torna-se um princípio estrutural e arquitectural (se assim o podemos designar) da sua poética, num sentido ambíguo. Tanto aparece como forma de desfiguração da harmonia e da totalidade, para dar lugar a uma paisagem devastada, como se refere à experiência da dilaceração da língua, da sua língua materna, na qual ele escreve o poema. E, sob esse ponto de vista, a alegoria atinge aqui uma violência inédita. O horror (e a violência) é o de uma profunda contradição vivida na pele. A língua em que Celan escreve é a língua materna, a dos enleios afectivos e da pertença, a do reconhecimento, é a mesma língua dos que levam a

\footnotetext{
${ }^{19}$ Silbermann, Edith, Op. Cit., p. 13.
} 
cabo o extermínio. No capítulo de Bollack, intitulado "Circuncidar el aléman" (Bollack, 2005), o autor refere precisamente esse esforço para conferir à língua alemã uma tonalidade judaica, para a afastar, assim, da língua dos nazis. A estruturação dos poemas de Celan obedece a essa intenção, como uma forma de "deslocamento" da língua, pois essa é a ferida profunda de Celan. Derrida refere essa questão, igualmente, na sua entrevista, já aqui citada. A clivagem que se instala na língua alemã é, ela própria, portadora de uma equivocidade, em que cada signo remete para outro (e, portanto, alegórica, no sentido em que Benjamin define a alegoria), procurando Celan, na língua alemã, uma forma de ir ter com a tradição judaica e bíblica (a tradição mística e a própria cabala). Não existe um ponto de repouso na poética de Celan, precisamente porque essa equivocidade confere à linguagem, ao verso, uma estranheza que lhe advém dessa dilaceração interna, proveniente da contradição interna, da proliferação dos sentidos, pela crueza da língua. Há um gesto, uma intenção, que é a de forçar a linguagem a significar. E esse gesto, mais do que poético, é também um gesto ético, que procura um sentido, um destino para o humano, através dos escombros e da catástrofe. Só existe, e Celan sabe disso, um gesto ético capaz de resgatar as vítimas da catástrofe da história e esse gesto é o da rememoração, como forma de não ser conivente com o esquecimento, como celebração, mas também como forma de nos obrigar a olhar o insustentável. A linguagem que convém a este testemunho é, ela própria, contaminada e Celan sabeo, daí a ameaça iminente do mutismo, o peso insustentável do que não pode ser dito, mas que também não pode ser esquecido. O mutismo de que fala Celan, essa sombria ameaça que paira sobre a linguagem, remete-nos também para outros textos, profundamente alegóricos, de Walter Benjamin. Relembre-se o mutismo da natureza triste e não nomeada, a natureza "sem voz" de que fala Benjamin no texto "Sobre a Linguagem em Geral e sobre a Linguagem Humana" ou nessa mesma tristeza da natureza muda, no texto "Origem do Drama Trágico Alemão" ou, ainda, no mutismo dos soldados que regressam das trincheiras, na Primeira Guerra Mundial, no texto "O Narrador". É sobretudo neste último que reconhecemos um paralelo com o "mutismo" de Celan. Ele resulta, com efeito, da perda da experiência autêntica ou, dizendo de outro modo, da "experiência do choque". Esta é, em Celan, a própria expressão da vivência da catástrofe. E o poema tende para a mudez, para uma impossibilidade, ainda que o gesto ético seja, como vimos anteriormente, o de 
"sair de si" e "ir a caminho do outro". Só assim se cumpre o destino do poema, salvar os que estão destinados à morte e ao esquecimento. Por isso, o poema "luta" por ir a caminho do outro, num gesto alegórico e derradeiro: o da passagem do testemunho. Paradoxalmente, só ele, o poema, pode salvar as vítimas do "Mestre que vem da Alemanha" e redimi-las, salvando-as do "olho do tempo" ${ }^{20}$, esse que nos "olha de través".

${ }^{20}$ Alusão ao poema "Olho do Tempo", na tradução de Yvette Centeno, in Sete Rosas Mais Tarde, p. 59. 


\section{BIBLIOGRAFIA}

Adorno, T. (2011). Teoria Estética. Lisboa: Edições 70.

Agamben, G. (2003). Ce qui reste d'Auschwitz. Paris: Rivages.

Agamben, G. (1991). Le Langage et la Mort. (M. Rayola, Trad.) Paris: Christian Bourgois éditeur.

Barroso, M. d. (s.d.). Todesfuge, de Paul Celan. Obtido de Triplo V: http://triplov.com/letras/maria_do_sameiro/celan/paul_celan.htm

Benjamin, W. (2006). A Modernidade (Obras Escolhidas de Walter Benjamin) (Vol. 3). (J. Barrento, Ed., \& J. Barrento, Trad.) Lisboa: Assírio \& Alvim.

Benjamin, W. (2004). A Origem do Drama Trágico Alemão (Obras Escolhidas) (Vol. 1). (J. Barrento, Trad.) Lisboa: Assírio \& Alvim.

Benjamin, W. (1991). Écrits Français. Paris: Gallimard.

Benjamin, W. (1972). Gesammelte Schriften V, 1, 2. Frankfurt: Suhrkamp Verlag.

Blanchot, M. (1984). Le Dernier à Parler. Paris: Fata Morgana.

Bollack, J. (2005). Poesía contra poesía. Celan y la literatura. (A. Pons, Ed.) Madrid: Trotta.

Bonnefoy, Y. (2007). Ce qui alarma Paul Celan. Paris: Galilée.

Cantinho, M. J. (2012). A Frágil Luz que nos espera. Revista Golpe d'asa , 1.

Celan, P. (1997). A Morte é uma Flor. Lisboa: Cotovia.

Celan, P. (2002). Le Méridien \& Autres Proses. (J. Launay, Trad.) Paris: Éditions du Seuil.

Centeno, Y. (1996). Introdução. In P. Celan, Sete Rosas mais tarde. Lisboa:

Cotovia.

Cohen-Levinas, D. (2001). Um passo mais para o Estrangeiro - Levinas perante Celan. In Vários, Entre Reconhecimento e Hospitalidade. 2011: Edições 70.

Derrida, J. (1986). Schibboleth pour Paul Celan. Paris: Galilée.

Forster, R. (2009). Los Hermeneutas de la Noche - De Walter Benjamin a Paul Celan. Madrid: Editorial Trotta.

Gesammelte Schriften, /1972FrankfurtSuhrkamp Verlag

Guerreiro, A. (2000). O Acento Agudo da Actualidade. Lisboa: Cotovia. 
Lacoue-Labarthe, P. (1986). La Poésie comme Expérience. Paris: Christian Bourgois.

Levinas, E. (2003). Paul Celan de L'être à l'Autre. Paris : Fata Morgana.

Paul Celan, N. S. (1995). Correspondence. New York: The sheep Meadow Press.

Paul Celan, Poet, Survivor, Jew 2001 New Haven and LondonYale University Press

Rencontre avec Paul Celan Europe 332

Sete Rosas mais Tarde 1996 Lisboa Cotovia

Steiner, G. (1969). Langage et Silence. Paris: Éditions du Seuil.

Szondi, P. (2003). Celan Studies. Stanford, California: Stanford University Press.

Vários. (Janvier-Février de 2001). Europe - Revue littéraire mensuelle. Paris: Europe. 